\title{
Numerical evaluation of the plastic hinges developed in headed stud shear connectors in composite beams with profiled steel sheeting
}

\author{
V. Vigneria*, C. Odenbreit ${ }^{\mathrm{a}}$, M. Braun ${ }^{\mathrm{a}}$ \\ aArcelorMittal chair of steel and facade, University of Luxembourg, Luxembourg \\ *corresponding author, valentino.vigneri@uni.lu
}

\begin{abstract}
For composite beams using novel steel sheeting, the current Eurocode 4 rules sometimes overestimate the load bearing capacity of the shear connector. This is due to the larger rib heights and the smaller rib widths in comparison with the old studies, which have been carried out to calibrate the current design equations. The RFCS Project "DISCCO" investigated this phenomena and the working group under mandate M515, $\mathrm{CEN} / \mathrm{TC} 250 / \mathrm{SC} 4 / \mathrm{SC} 4 . \mathrm{T} 3$ is enhancing this equation and working on a proposal to be taken over in the new version of Eurocode 4.

The proposed new equation covers the failure behaviour of the shear connection more in detail. The test results show, that the failure consists in a combined concrete cone and stud in bending. Due to the geometry of novel steel sheeting, the load bearing capacity of the headed stud shear connector is no more limited by its shear capacity, but by its bending capacity.

A 3D non-linear finite element model is developed and validated through the support of the DISCCO push-out tests. A good agreement between numerical and experimental results in terms of force-slip behaviour is achieved. Special attention of this work lies on the numerical evaluation of the number of plastic hinges $n_{y}$ : a stress-based procedure is presented and the results are compared to the equations presented for new Eurocode 4.

The numerical simulations show that the upper plastic hinge moves up as the slip increases due to the progressive crushing of the concrete in the rib. From the parametric study, it turns out that $n_{y}$ is linearly proportional to the embedment depth. Compared to pre-punched hole decking, through-deck welding specimen activates less plastic hinges in the studs because of the higher stiffness provided at the base of the stud.
\end{abstract}

Keywords: Push-out test; shear stud; mechanical model; numerical model; shear connector with profiled sheeting.

\section{Introduction}

Steel-concrete composite solutions are massively used in several sectors, especially for non-residential multi-storey buildings. Their success is mainly due to a good balance between structural performance (e.g. strength and stiffness) and economical efficiency. In view of that, more and more studies have recently focused on developing more advanced and precise technical regulations in order to increase the efficiency of steel-concrete solutions.

This contribution will focus on headed stud shear connectors used in composite beams with profiled steel sheeting. The steel studs are welded on the steel beam flange and are able to transfer the shear force between the concrete slab and steel beam.

The design load-bearing resistance of shear connectors with headed studs shear connectors and profiled steel sheeting is currently calculated through the formulation presented in EN1994-11 [1]. That is none other than an extension of the formula proposed for solid slabs, reduced by a coefficient $k_{t}$ calibrated in the early 1990s. Despite its simplicity, current regulations does not lead to safe and efficient results for some 
modern steel decking. Therefore, several recent projects, such as the RFCS project DISCCO, are aimed at developing new refined rules taking into account the mechanical behaviour of the members.

Recent push-out tests showed that "new" failure modes may occur when deep profiled steel sheeting are used: concrete cone failure in combination with a plastic bending of the headed shear studs. Therefore, the new proposed equations presented in this paper will take into account these two, parallel acting, mechanisms.

This work is mainly focused on the evaluation of the number of plastic hinges developed in the studs, assessed through numerical finite element models.

\section{Experimental investigation}

Among other experimental works, the project DISCCO (Development of Improved Shear Connector rules in COmposite beam) provided interesting results from several push-out tests [2]. A typical specimen of the tests is shown in Fig. 1.

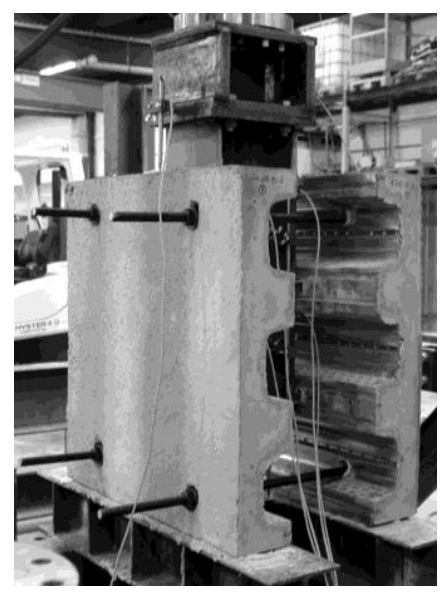

Fig. 1. Specimen of DISCCO project using $80 \mathrm{~mm}$ deep steel sheeting.

It was observed that the specimen generally exhibit concrete cone failure and plastic bending of the studs. An important outcome is that deeper steel sheeting leads to the formation of one plastic hinge at the bottom of the studs. Unlike deep sheeting, composite beams using low profiled steel sheeting are generally able to develop two plastic hinges as shown (Fig. 2) due to the higher stiffness provided by the deeper embedment of the studs in the concrete topping.

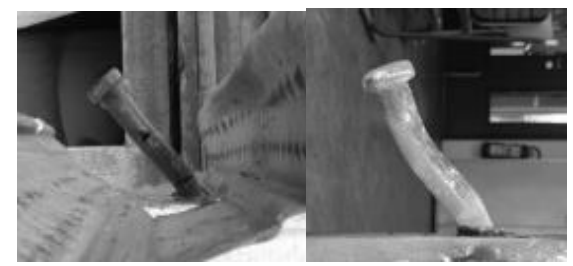

Fig. 2. Plastic deformation of the stud with one and two plastic hinges.

\section{Proposed analytical equations}

\subsection{General}

Based on the failure modes observed, a new mechanical model has been proposed [3] and developed. Unlike the current rules in EN 19941-1 [1], this model is able to capture a more realistic failure behaviour of the connection. Firstly, the contribution of the concrete cone is considered as the elastic bending resistance of an equivalent cantilever, see Fig. 3. The shear force $P_{c}$ carried by the concrete cone per stud is given by the Eq. 1:

$$
P_{c}=\frac{f_{c t m} W}{n_{r} h_{p}}
$$

$f_{c t m}$ is the mean tensile strength of the concrete, $W$ indicates the section modulus of the concrete cone failure surface defined according to Eq. 2 and $n_{r}$ is the number of studs per rib.

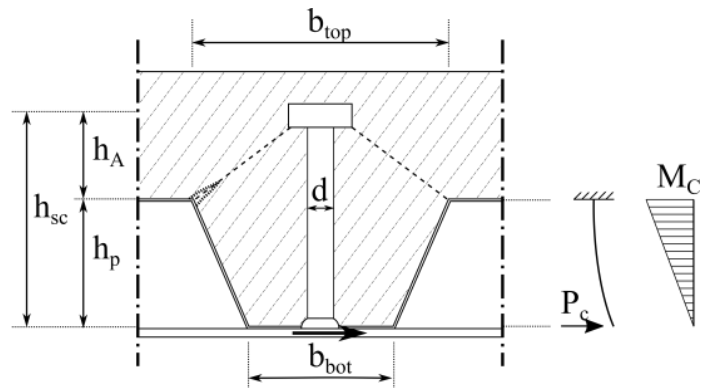

Fig. 3. Equivalent static scheme of the concrete rib of the shear connector.

$$
W=\left[2.4 h_{s c}+\left(n_{r}-1\right) e_{t}\right] \frac{b_{\max }^{3}}{6 b_{\text {top }}}
$$

The parameters indicated above are based on the failure surface of the concrete cone that was firstly estimated by Lloyd and Wright [4] and then simplified [3] as shown in Fig. 4. 


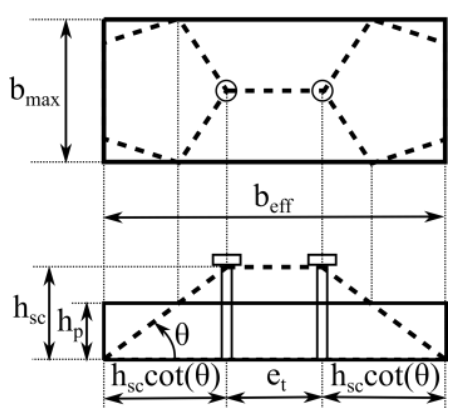

Fig. 4. Approximated and simplified failure surface of the concrete cone.

The influence of the studs is accounted by considering an equivalent beam with one or two plastic hinges. These two extreme cases and the relative static schemes are shown in Fig. 5 and Fig. 6 respectively.

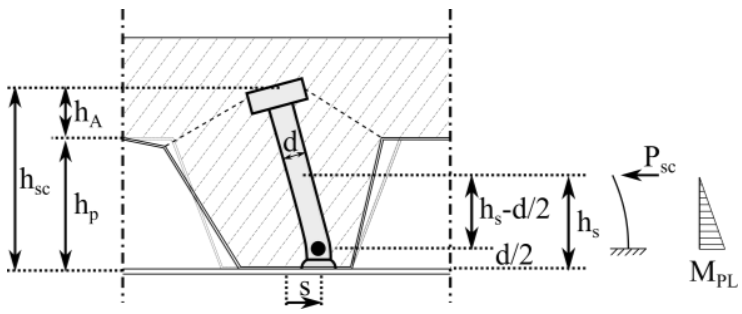

Fig. 5. Equivalent static scheme of the steel stud with one plastic hinges.

Assuming that the plastic bending moment of the cross section $M_{p l}$ is reached at failure, a general analytical expression of the shear force $P_{s c}$ carried by the stud can be derived:

$$
P_{s c}=\frac{n_{y} M_{p l}}{h_{s}-d / 2}
$$

$n_{y}$ indicates the number of plastic hinges developed in the studs at failure.

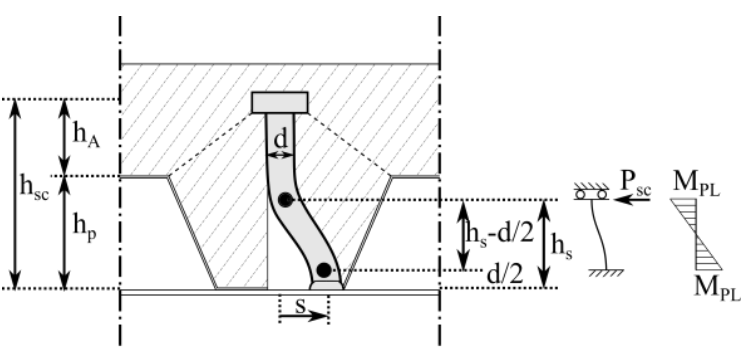

Fig. 6. Equivalent static scheme of the steel stud with two plastic hinges.

The resultant shear force of the connection per stud will be given by:

$$
P=P_{c}+P_{s c} \leq P_{s h}
$$

Where $P_{s h}$ is the pure shear resistance of the stud. Therefore, the analytical load bearing resistance of the connection per stud is given by:

$$
P=\min \left\{\begin{array}{c}
\frac{f_{y} A}{\sqrt{3}} \\
\alpha_{c 2} k_{u}\left(\frac{f_{c t m} W}{h_{p} n_{r}}+\frac{n_{y} M_{p l}}{h_{s}-d / 2}\right)
\end{array}\right.
$$

Where $A$ is the area of the cross section of the stud. The coefficient of reduction $\alpha_{c 2}$ and $k_{u}$ accounts for the relaxation of the concrete and the position of the studs in the rib. The relative design resistance equations presented by CEN/TC250/SC4.PT3 for the revision of the rules of Eurocode 4 is not considered in this contribution as the principal objective is the description of the mechanical behaviour of the studs.

\subsection{Prediction of the number of plastic hinges in the studs $n_{y}$}

The evaluation of the parameter $n_{y}$ is important and needs to be carefully assessed. From a mechanical point of view, the development of the upper plastic hinge in the stud is mainly governed by the stiffness provided by the concrete topping: if enough embedment depth is ensured, the concrete topping behaves as a fixed constraint and no rotation is allowed in the stud at the height of the second plastic hinge, see Fig. 6. The less is the embedment depth $h_{A}$, the less rotational stiffness is provided and then the second hinge cannot fully develop.

For one stud, an embedment depth of at least $2 d$ is always sufficient to ensure the formation of 2 plastic hinges. Conversely, for two studs per rib, $n_{y}$ is assumed to be linearly proportional to the embedment depth $h_{A}$ as expressed in Eq.6.

$$
n_{y}= \begin{cases}2 & n_{r}=1 \\ 1+\frac{h_{A}-2 d}{0.52 d} \leq 2 & n_{r}=2\end{cases}
$$

\section{Finite element model}

\subsection{General}

The software Abaqus 6.14-5 is chosen for numerically reproducing the push-out tests. Based on former numerical works performed on push-out tests [5], a 3D non-linear finite element model with dynamic-explicit solver is used. This helps to overcome convergence problems that generally arise at contact/interaction interfaces.

The model adopted consists of 5 instances: concrete slab, steel beam and studs tied together, profiled steel decking, reinforcement mesh and 
steel plate. The key parameters of each element are listed in Table 1.

Table 1. Modelling parameters of the elements

\begin{tabular}{ccc}
\hline Instance & Mesh type & $\begin{array}{c}\text { Failure } \\
\text { criteria }\end{array}$ \\
\hline Slab & C3D8R & CDP \\
\hline $\begin{array}{c}\text { Studs and } \\
\text { beam }\end{array}$ & C3D8R & Von Mises \\
\hline Rebars & T3D2 & Von Mises \\
\hline Sheeting & S4R & Von Mises \\
\hline Plate & C3D8R \\
\hline
\end{tabular}

Due to the symmetricity of the push-out test, only a quarter of the specimen has been reproduced (Fig. 7) with proper boundary conditions. All the nodes on the bottom surface of the base steel plate are fixed in all directions. All nodes of surface 1 are fixed in $\mathrm{X}$ direction and the nodes of surface 2 are restrained in $Y$ direction in order to reproduce the symmetry conditions.

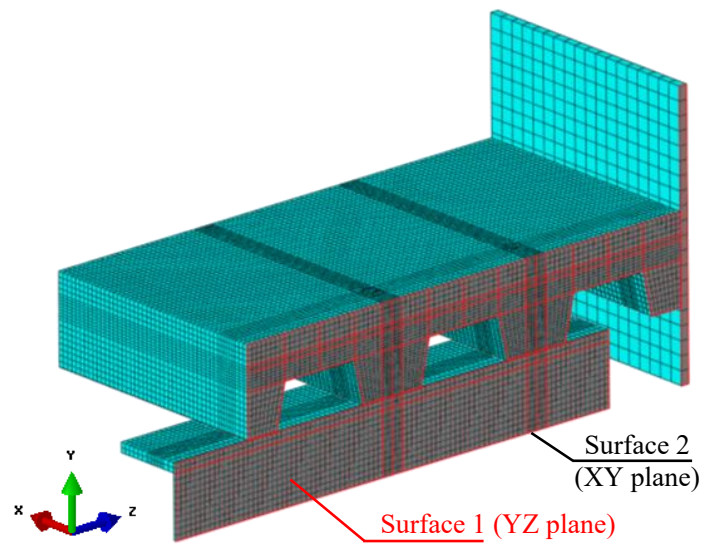

Fig. 7. Mesh of the finite element model (specimen DISCCO 3-02).

Except for the base steel plate, an average mesh size of $10 \mathrm{~mm}$ is assessed to be suitable. General contact algorithm is adopted for modelling all the contacts. In this work, the default normal behaviour is considered for all the interactions and no tensile stress is allowed to be transferred. Penalty friction formulation is chosen for the tangential behaviour with a friction coefficient of 0.5 and 0.3 for steelconcrete and steel-steel interactions respectively. For through-deck welded specimen, a tie constraint is enforced between the bottom of the stud shank and the decking hole. Conversely, no interaction/contact is considered in pre-punched hole specimen.

\subsection{Load application}

Due to the dynamic nature of the solver adopted, the loading rate, time period and mass scaling factor need to be carefully evaluated to minimize the dynamic-inertial effects throughout the numerical simulation. In order to ensure a quasi-static process, the kinetic energy should not exceed $5 \%$ fraction of the internal energy of the whole system.

A suitable loading rate $v$ and time period $T$ are chosen as a function of the maximum end slip analysed (see Table 2).

Table 2. Key parameters for load application

\begin{tabular}{ccc}
\hline $\begin{array}{c}\text { Max. end slip } \\
S_{\text {end }}[\mathbf{m m}]\end{array}$ & $\begin{array}{c}\text { Time } \\
\text { period } \boldsymbol{T}[\mathrm{s}]\end{array}$ & $\begin{array}{c}\text { Loading rate } \\
\boldsymbol{v}_{0}[\mathbf{m m} / \mathbf{s}]\end{array}$ \\
\hline 10 & 20 & 0.5
\end{tabular}

The loading rate is introduced gradually by using a proper smooth step function for a relatively small time $t_{0}<<T$. No transversal load is applied as its influence is not investigated in this work.

\subsection{Material modelling}

As already shown in previous numerical study on push-out test [5], the use of Concrete Damage Plasticity (CDP) model leads to satisfying results. Therefore, $\mathrm{CDP}$ is chosen for modelling the slab in this study. The plasticity parameters adopted in the model are shown below, in Table 3.

Table 3. Plasticity parameters of CDP model [6]

\begin{tabular}{ccccc}
$\psi[\mathrm{deg}]$ & $\boldsymbol{e}[-]$ & $\boldsymbol{f}_{b 0} / f_{c 0}[-]$ & $\boldsymbol{K}_{c}[-]$ & $\boldsymbol{\mu}[-]$ \\
\hline 38 & 0.1 & 1.16 & 0.67 & -
\end{tabular}

Based on the investigations shown in [7] and [8], the following equations for uniaxial compressive stress-strain relation $\sigma_{c^{-}} \varepsilon_{c}$ is implemented:

$$
\sigma_{c}=f_{c} \frac{n\left(\frac{\varepsilon_{c}}{\varepsilon_{c 0}}\right)}{(n-1)+\left(\frac{\varepsilon_{c}}{\varepsilon_{c 0}}\right)^{n}}
$$

Where $f_{c}$ and $\varepsilon_{c 0}$ are respectively the concrete uniaxial compressive strength and the relative strain. The parameter $n$ is given by:

$$
n=1.5 \cdot\left[0.058 f_{c}(M P a)+1\right]
$$

The compression damage parameter $d_{c}$ is calculated through Eq. 9 [9], where $b_{c}$ is taken 
equal to 0.7 and $\varepsilon_{c}^{p l}$ indicates the plastic compressive strain.

$$
d_{c}=1-\frac{\sigma_{c} E_{c}^{-1}}{\varepsilon_{c}^{p l}\left(1 / b_{c}-1\right)+\sigma_{c} E_{c}^{-1}}
$$

Conversely, uniaxial post-crack behaviour of concrete is implemented by using an exponential stress-displacement $\sigma_{t}-w$ (i.e crack opening) function [10] shown in Eq. 10.

$$
\left\{\begin{array}{l}
\sigma_{t}=f_{t}\left[f(w)-\left(\frac{w}{w_{c}}\right) f\left(w_{c}\right)\right] \\
f(w)=\left[1+\left(3 w / w_{c}\right)^{3}\right] \exp \left(-\frac{6.93 w}{w_{c}}\right) \\
w_{c}=5.14 G_{f} / f_{t}
\end{array}\right.
$$

Where $w_{c}$ is the critical crack opening at which no tensile stress can be transferred. $G_{f}$ is the fracture energy which is estimated according to Model Code 90 [11]. The tensile damage parameters is assumed to be linearly proportional to the tensile stress after cracking:

$$
d_{t}= \begin{cases}1 & w=0 \\ 1-\frac{\sigma_{t}(w)}{f_{t}} & w>0\end{cases}
$$

Measured values of Young Modulus and concrete strength of concrete are considered in the model and in the parametric studies. Poisson ratio is assumed to be 0.2 .

The steel grade of the beam, decking and studs is modelled with a bilinear stress-strain law and Von Mises criteria: the main properties are listed in Table 4. A bilinear stress-strain law is also assumed for the reinforcement bars where $f_{y}=500 \mathrm{MPa}$ and $f_{u}=550 \mathrm{MPa}$.

Table 4. Material properties of steel elements

\begin{tabular}{c|ccc}
\hline Property & Beam & Decking & Stud \\
\hline$f_{y}[M P a]$ & 424 & 350 & 470 \\
$f_{u}[M P a]$ & 525 & 420 & 550 \\
$\varepsilon_{u}[-]$ & 0.16 & 0.16 & 0.2
\end{tabular}

\subsection{Validation}

In order to validate the numerical model presented, two tests from DISCCO project are taken as a reference: the results are compared in terms of resistance, stiffness and then force-slip behaviour. The data and the resistance of the push-tests reproduced are listed in Table 4. As shown in Fig. 8 and Fig. 9, a good agreement between experimental and numerical results is

\begin{tabular}{|c|c|c|}
\hline Reference test & $3-01-3$ & 3-02 \\
\hline$h_{p}[\mathrm{~mm}]$ & 80 & 80 \\
\hline$n_{r}[$ studs $/$ rib $]$ & 2 & 2 \\
\hline$d[\mathrm{~mm}]$ & 19 & 19 \\
\hline$h_{s c}[\mathrm{~mm}]$ & 118 & 123 \\
\hline Rebar mesh & $\begin{array}{c}\text { Q188A and } \\
\text { Q335A }\end{array}$ & Q188A \\
\hline Welding & $\begin{array}{c}\text { Through } \\
\text { deck }\end{array}$ & $\begin{array}{l}\text { Pre-punched } \\
\text { holes }\end{array}$ \\
\hline$f_{c m}[\mathrm{MPa}]$ & 40.4 & 42.6 \\
\hline$E_{c m}[\mathrm{MPa}]$ & 26800 & 28000 \\
\hline$P_{\operatorname{Exp}}[\mathrm{kN} / \mathrm{stud}]$ & 52.78 & 36.99 \\
\hline$P_{F e m}[\mathrm{kN} / \mathrm{stud}]$ & 55.93 & 38.00 \\
\hline$P_{F e m} / P_{E x p}[-]$ & 1.06 & 1.03 \\
\hline
\end{tabular}
achieved.
Table 5. Key parameters for validated push-out tests

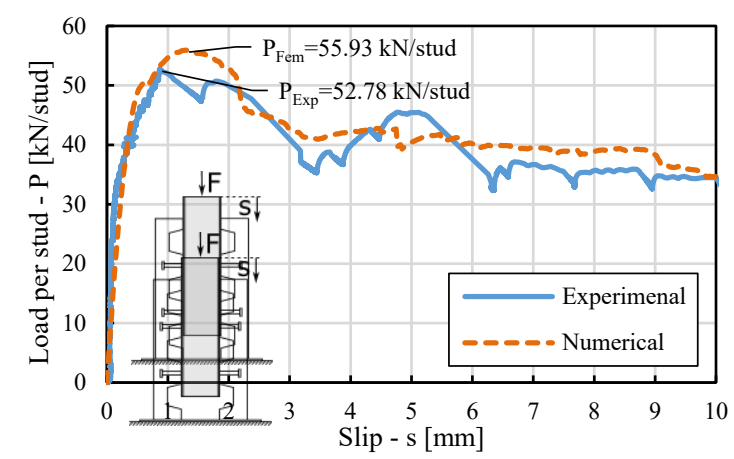

Fig. 8. Force-slip plot of DISCCO test 3-01-3.

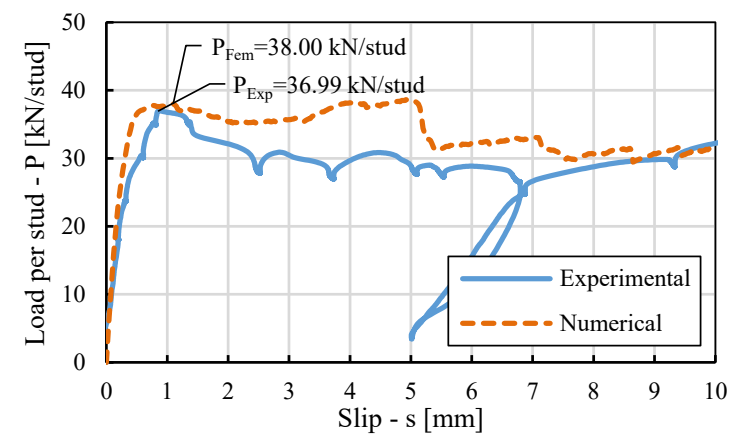

Fig. 9. Force-slip plot of DISCCO test 3-02.

\section{Numerical and analytical evaluation of the number of plastic hinges $n_{y}$}

\subsection{Stress-based method procedure}

In order to quantify the number of plastic hinges in the studs, a stress-based method is used and presented in this paragraph. First, the normal stress distribution is obtained in the numerical model by cutting the cross-section at which the second hinges develop (i.e. relatively high localized normal stresses). The feature PATH is needed to obtain the normal stress $\sigma_{N}$ along the central nodes, see Fig. 10. 

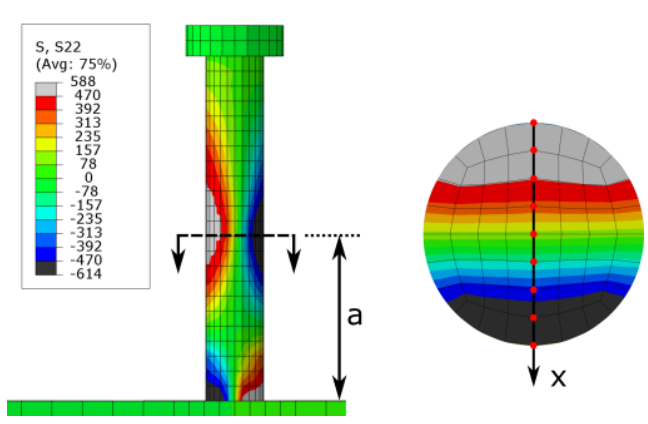

Fig. 10. Cross-section of upper plastic hinge with the relative path nodes.

Once the stress distribution $\sigma_{N}(x)$ is known, the bending moment can be calculated analytically by solving the following integral:

$$
M_{y} \int_{A}\left[\sigma_{N}(x) \cdot x\right] d A=\int_{-\frac{d}{2}}^{\frac{d}{2}}\left[\sigma_{N}(x) \cdot b(x) \cdot x\right] d x
$$

Where $b(x)$ is the width of the circular crosssection, which can be defined as a function of $d$ and $x$ :

$$
b(x)=\frac{1}{2} \sqrt{\frac{d^{2}}{4}-x^{2}}
$$

As the normal stresses are locally calculated in the nodes, $\sigma_{N}(x)$ will be a piecewise linear function. Therefore, it is convenient to integrate on each interval $i$, see Fig. 11.

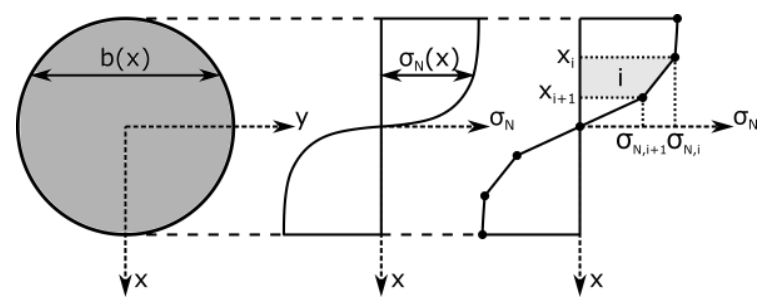

Fig. 11. Real and numerical discrete normal stress distribution along the cross-section of the stud.

Based on the functions illustrated above, the integral in Eq. 12 can be written as follows:

$$
M_{y}=\sum_{i} \int_{x_{i}}^{x_{i+1}}\left\{\left[\sigma_{N, i}+\sigma_{N, i}^{\prime}\left(x-x_{i}\right)\right] \frac{x}{2} \sqrt{\frac{d^{2}}{4}-x^{2}}\right\} d x
$$

The integral expression is analytically solvable and the resulting bending moment resistance will be equal to:

$$
\begin{aligned}
M_{y}=\frac{1}{12} \sum_{i}\left\{3 \sigma_{N, i}^{\prime} r^{4}\right. & \sin ^{-1}\left(\frac{x}{r}\right) \\
& +\left[\left(-6 \sigma_{N, i}^{\prime} x-6 \sigma_{N, i}^{\prime} x_{i}\right.\right. \\
& \left.\left.-8 \sigma_{N, i}\right)\left(r^{2}-x^{2}\right)^{\frac{3}{2}}\right] \\
& \left.+3 \sigma_{N, i}^{\prime} r^{2} x \sqrt{r^{2}-x^{2}}\right\}
\end{aligned}
$$

To compute the fraction of plastic hinge developed at a certain cross-section, the bending moment capacity in Eq. 15 is compared to the theoretical plastic capacity of the stud $M_{y, P l}$. Assuming that one plastic hinge always develops at the bottom, the number of plastic hinges for each stud will be equal to:

$$
n_{y}=1+\frac{M_{y}}{M_{y, P l}} \leq 2
$$

Where $M_{y, P l}=f_{y} d^{3} / 6$ and $M_{y}$ is evaluated at the height where the highest normal stresses are observed (i.e. $2^{\text {nd }}$ plastic hinge location).

\subsection{Parametric analysis}

In addition to the two validated tests already performed, 4 numerical simulations are carried out. Only push-out tests with two studs per rib are reproduced in order to check the validity of the linear expression of Eq. 6. The parameters analysed are the type of welding and the embedment depth. However, the latter is changed by increasing/decreasing the height of the stud $h_{s c}$.

The slip values of 1.5, 3 and $6 \mathrm{~mm}$ are taken as a reference: this allows to visualize the evolution of the plastic hinge (Fig. 12 and Fig. 13) during the test and gives a better understanding of the load-bearing mechanism of the studs.

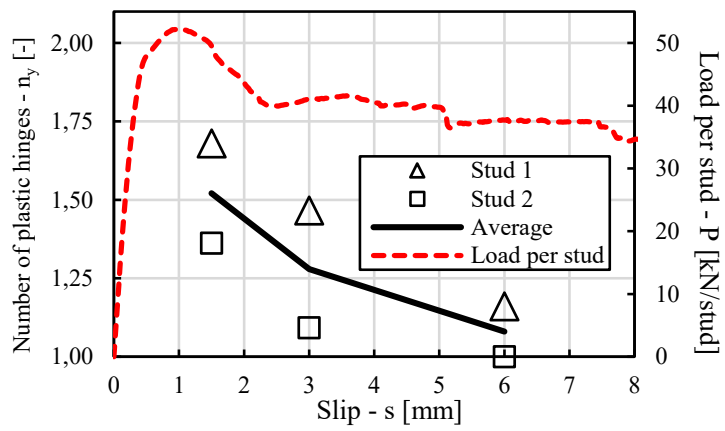

Fig. 12. Evolution of $n_{y}$ in low embedment depth specimen $\left(h_{s c}=110 \mathrm{~mm}\right)$. 


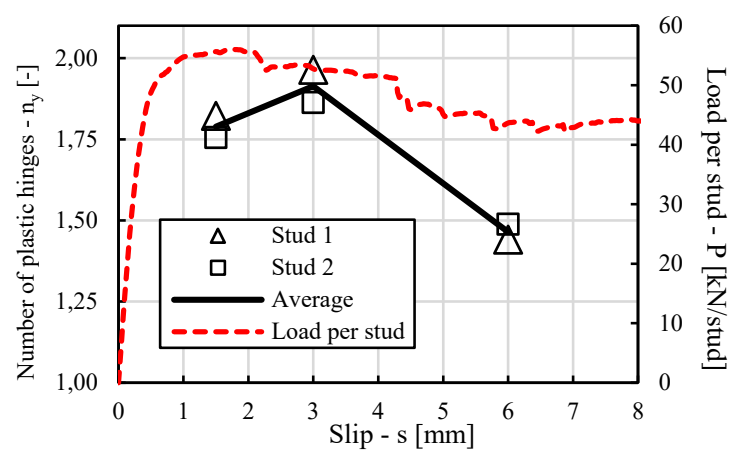

Fig. 13. Evolution of $n_{y}$ in high embedment depth specimen $\left(h_{s c}=130 \mathrm{~mm}\right)$.

It is clear that the ductility of the shear connector is related to the evolution of the plastic hinges. Furthermore, the normal stress $\sigma_{N}(x)$ contour plot of the studs over the simulation shows that the upper plastic hinges literally moves up until it completely "vanishes" once the head of the stud rotates due to the local crushing of the underlying concrete (see Fig. 14). This so called "travelling plastic hinge" is the consequence of the progressive concrete crushing which leads to a gradual change of the stiffness centre.

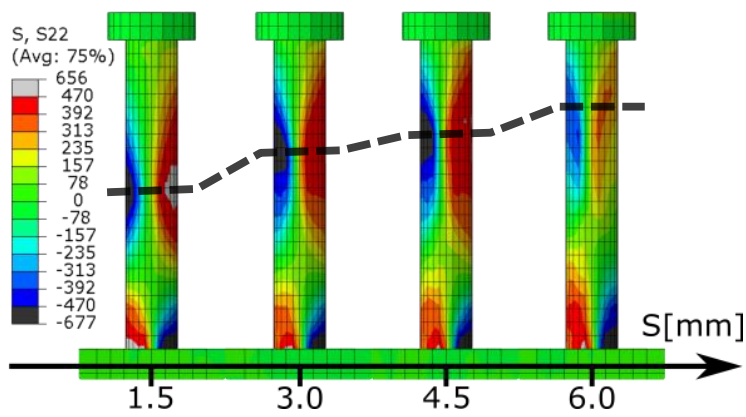

Fig. 14. Normal stress contour at an end slip of 1.5, 3, 4.5 and $6 \mathrm{~mm}$ (3-02 test [2]).

The data and the results of the parametric analysis are listed below in Table 6, where the normalized embedment depth $h_{A, N}$ is defined as follows:

$$
h_{A, N}=\frac{h_{A}}{2 d}=\frac{h_{s c}-h_{p}}{2 d}
$$

In order to quantify $n_{y}$, the reference slip of 6 $\mathrm{mm}$ is chosen to be the most suitable as current design rules [1] considers it as "target slip" to ensure the ductility of the connection.
Table 6.Number of plastic hinges $n_{y}$ from the numerical parametric analysis

\begin{tabular}{|c|c|c|c|c|c|c|}
\hline \multirow{2}{*}{$\begin{array}{c}\text { Welding } \\
h_{s c} \\
{[\mathrm{~mm}]}\end{array}$} & \multicolumn{3}{|c|}{ Through deck } & \multicolumn{3}{|c|}{ Pre-punched holes } \\
\hline & 110 & 118 & 130 & 110 & 123 & 130 \\
\hline$h_{A, N}[-]$ & 0.79 & 1.00 & 1.32 & 0.79 & 1.13 & 1.32 \\
\hline 1.5 & 1.52 & 1.70 & 1.79 & 1.83 & 1.85 & 1.89 \\
\hline$\Xi$ & 1.28 & 1.56 & 1.91 & 1.79 & 1.96 & 1.98 \\
\hline 6 & 1.08 & 1.33 & 1.46 & 1.41 & 1.81 & 1.99 \\
\hline
\end{tabular}

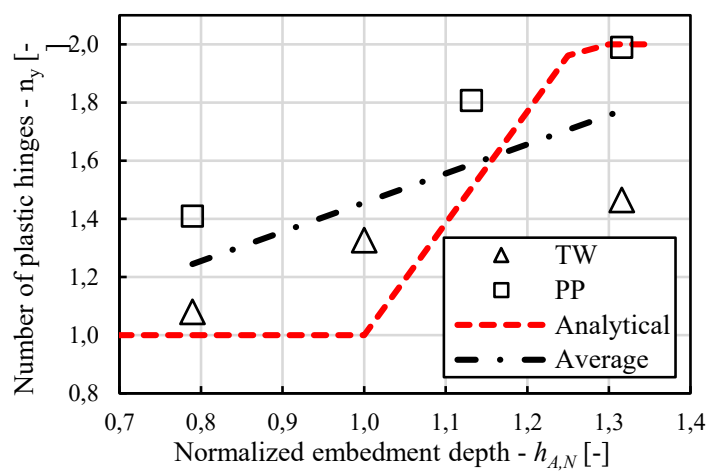

Fig. 15. Comparison between numerical results and analytical for predicting $n_{y}$.

As expected, compared to through-deck welding, pre-punched hole specimen exhibits higher number of plastic hinges at all displacements (Table 6). This is due to the extra stiffness provided by the welding between the decking and the stud that delays the progressive motion of the second hinge up to the slab. Compared to the linear analytical expression presented in section 3 (Eq. 6), the numerical parametric study gives a lower slope of the function $n_{y}\left(h_{A}\right)$. However, additional geometric and mechanical parameters need to be assessed in order to estimate $n_{y}$ more accurately.

\section{Conclusions}

The main outcomes of this contribution are:

- Based on the results observed in the pushout tests of the project DISCCO [2], a mechanical model and the corresponding analytical equations for predicting the loadbearing resistance of shear connection with profiled steel sheeting are developed;

- A 3D finite element model using dynamic/explicit solver is presented and properly validated against DISCCO pushout tests in terms of stiffness, capacity and ductility (up to $10 \mathrm{~mm}$ end-slip); 
- An analytical stress-based method is proposed and used to extrapolate the number of plastic hinges in the studs from the numerical model;

- All the numerical simulations performed show that the upper plastic hinge moves up as the slip increases. This is a consequence of the progressive crushing of the concrete in the rib leading to a relocation of the centre of stiffness;

- According to the proposed stress-based procedure, the number of plastic hinges at 6 $\mathrm{mm}$ slip is approximately linearly proportional to the embedment depth;

- Compared to pre-punched hole decking, through-deck welding specimen exhibit lower values of activated plastic hinges due to the higher stiffness provided at the base of the stud.

\section{Outlook}

The influence of further design parameters such as the position of the reinforcement, the number of studs per rib, concrete strength is still under investigation. Based on supplementary numerical studies, a refined mechanical model will be developed.

\section{Acknowledgement}

The RFCS project "DISCCO" was supported by the grant agreement number RFSR-CT-2012-00030. Further, the authors gratefully acknowledge the support of ArcelorMittal Global R\&D, Long Products Luxembourg.

\section{References}

[1] EN 1994-1-1, Eurocode 4: Design of composite steel and concrete structures - Part 1-1: General rules and rules for buildings, 2004.
[2] Odenbreit C, Kuhlmann U, Nellinger S, Eggert F. Development of improved shear connection rules in composite beams - Deliverable D1.3: Report on Push-out test results; 2015.

[3] Odenbreit C, Vigneri V, Amadio C, Bedon C, Braun M. New mechanical model to predict the load bearing resistance of shear connectors with modern forms of profiled sheeting. Perth; 2018.

[4] Lloyd R, Wright HD. Shear connection between composite slabs and steel beams. Journal of Constructional Steel Research 1990;15(4):255285.

[5] Quareshi J. Finite element modelling of steelconcrete composite structures. Leeds; 2010.

[6] Dassault Systèmes Simulia. Abaqus Analysis User's Guide v6.14; 2014.

[7] Popovics S. A numerical approach to the complete stress-strain curve of concrete. Cement and Concrete Research 1973;3:583-599.

[8] Thorenfeldt E, Tomaszewicz A, Jensen JJ. Mechanical properties of high strength concrete and application in design. Symposium on Utilization of High-strength Concrete. Trondheim; 1987.

[9] Birtel V, Mark P. Parameterised finite element modelling of RC beam shear failure. Abaqus Users' Conference; 2006.

[10] Cornelissen HAW, Hordijk DA, Reinhardt HW. Experimental determination of crack softening; 1986.

[11] C.E.I. CEB-FIP Model Code 1990. Design Code. London; 1993.

[12]EN 1992-1-1. Eurocode 2: Design of concrte structures - Part 1-1: General rules for Buildings; 2004.

[13] EN 1990. Eurocode 0: Basis of structural design; 2002.

[14] Nellinger S. On the behaviour of shear stud connections in composite beams with deep decking. Luxembourg; 2015.

[15] Lungershausen. Zur Schubtragfähigkeit von Kopfbolzendübeln. Ruhr Universität Bochum; 1988. 